\title{
Smoke Control through Ventilation Systems on the Fire-Induced Conditions in a Stairwell
}

\author{
Aristides Lopes da Silva, Shengwu Xiong, and Hussain Aamir
}

\begin{abstract}
To understand the fire behavior depending on the structure of the building, it is extremely important, not only to analyze and interpret the ventilation systems, but also to understand the forms of support for smoke control and analyze the best strategy evacuation in case of emergency of zones of high flow of occupants.

With the evolution of hardware and software, the technique of numerical simulation has been widely applied in the simulation of reconstruction of fire and ventilation studies, making it a useful tool in analyzing the design features, ultimately improving the visibility of evacuation of occupants.

In this article is proposed a model that examines design issues related to mechanical ventilation systems, particularly associated with pressurization systems of stairwells, and also analyses a potential alternative approach, namely, a model that involves the supply and exhaust of high rates of air streams, providing clean air into the stairwell and thus the possibility of maximum dilution of any fumes that may be present. In order to introduce the study based on continuous model FDS, some examples of fire simulation scenarios in one of the stairwells of a building are presented. Also, natural ventilation, pressurization and dilution, are simulated as tested, with the aim of obtaining the optimal solution. Furthermore, the results are analyzed and compared. Finally, it is also addressing continuation studies.
\end{abstract}

Index Terms-CFD simulations, dilution system, FDS code, fire tests, mechanical exhaust.

\section{INTRODUCTION}

When there is a fire in a high building, for precautionary reasons, it's not advisable to use the elevators, so the stairs are the only way to evacuate a building, so within the stairwell environment, the visibility is a key factor for the occupants in case of emergency to safely evacuate the building.

On a related note to the security of a high building, a design in stair pressurization system has been used to prevent the entry of smoke on the stairs [1]. The stack effect can be highly possible to occur, especially in some countries in Asia, Europe and America, which usually happen due to differences in temperature between the inside and the outside, above $30^{\circ} \mathrm{C}$ [2]. In these types of buildings are more specific to more than 20 floors, the stairwell pressurization systems, are more complex to design, particularly related to the impact

Manuscript received February 7, 2015; revised November 19, 2015.

The authors are with the School of Computer Science and Technology, Wuhan University of Technology, China (e-mail: aristides.silva@docente.unicv.edu.cv, amirpkbcs@yahoo.com).

of the stack effect in maintaining uniform pressure in relation to the height of the building [3].

Despite this, the effectiveness of a stair pressurization system, depends mainly on keeping doors predominantly closed, so that can maintain a pressure differential where necessary, and thus prevents the entry of smoke inside the stairwell [4]. Keeping the doors open during the egress of occupant can become a problem particularly during a full evacuation of the building, or issues relating to structural damage to the stairs, would also severely compromise system performance.

The study model proposed in this paper particularly examines design issues associated with pressurizing systems of stairwells, and also analyses a potential alternative approach, namely, models involving supply and exhaust of high rates of air streams, providing clean air into the stairwell and thus the possibility of the maximum dilution of any fumes that may be present. Thus, based on Computational Fluid Dynamic Models and numerical simulations, is presented an improvement model of ventilation systems as an alternative approach. In this sense, the code used to simulate the dynamics of fire and smoke spread in this work was FDSv5.5.3.

The model shows that this system can control the different pressure on the top floors, and simultaneously the reduction of smoke on the stairs, in this sense, it is considered practical to build stairs in high buildings.

\section{Simulation Scenario}

The fire tests reported here have been carried out in one of the stairwells of a 21-storey building in Wuhan Hubei China with a global area of $2060 \mathrm{~m}^{2}$ Fig. 1(a). This building refers to the Technology Department of Wuhan University of Technology.

The, Fig. 1(e) shows the geometric model designed. The walls, floor and roof are made of concrete. There are ten grilled vents arranged at the lower parts of the walls, each vent has a dimension of $(0.5 \mathrm{~m} \times 0.4 \mathrm{~m})$, these vents are alternately positioned at $15 \mathrm{~cm}$ from the floor and wall, existing only in the pairs floors Fig. 1(b) and Fig. 1(c).

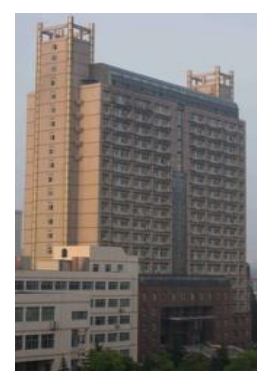

(a)

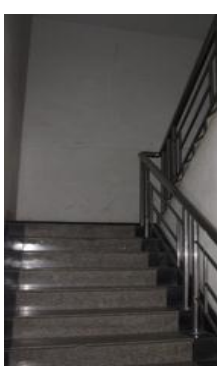

(b)

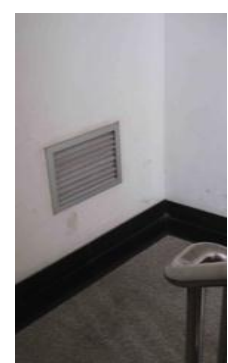

(c) 


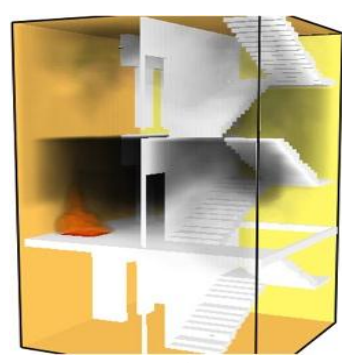

(d)

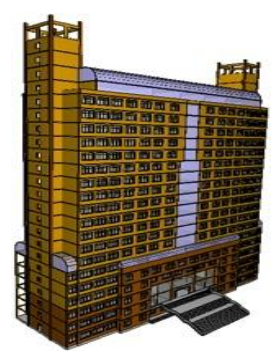

(e)
Fig. 1. Building under study in (a), odd floors in (b), pair floors in (c), partial model of the stairwell in (d) and FDS geometric model in (e).

In geometric modeling tested herein, the outside temperature in winter was assumed to be $-3{ }^{\circ} \mathrm{C}$. Based on standard document stipulated by the Chinese code GB50045-95 [5], the minimum output width of the stairs shall not be less than the values described in Table I (left side) The width of the main exit and measures of stairs per floor studied in this work are presented in Table I (right side), and in Fig. 1(d) is shown a partial image of the modeled stairwell.

TABLE I: STANDARD MEASUREMENTS \& MEASUREMENTS OF THE STAIRCASE PROJECT

\begin{tabular}{ll|lll}
\hline \hline \multicolumn{2}{l|}{ Minimum width of escape stairs } & \multicolumn{3}{|c}{ Measurements of the staircase project } \\
\hline Building type & $\begin{array}{l}\text { Minimum } \\
\text { exit width }\end{array}$ & $\begin{array}{l}\text { Width of } \\
\text { exit stair }\end{array}$ & \multicolumn{2}{l}{ Stairs per floor } \\
\hline Apartments & $1.1 \mathrm{~m}$ & \multirow{2}{*}{$1.2 \mathrm{~m}$} & Length & $5.8 \mathrm{~m}$ \\
Hospitals & $1.3 \mathrm{~m}$ & & Width & $2.8 \mathrm{~m}$ \\
Others & $1.2 \mathrm{~m}$ & & Height & $3.3 \mathrm{~m}$ \\
\hline \hline
\end{tabular}

\section{A. Numerical Simulation}

To explain the scenario, begin by pointing out that the simulation of the fire occurred in the technology department of Wuhan University of Technology, Hubei China, specifically in the lobby to the access of one of the side stairs of the building, on the $12^{\text {th }}$ floor, Fig. 1(a).

Initially the power of the fire is $5000 \mathrm{KW}$, equivalent to $5 \mathrm{MW}$. The building environment temperature in winter on the day of the event was considered $-3^{\circ} \mathrm{C}$ outdoor, and to define the inner temperature of $18^{\circ} \mathrm{C}$ was used "init region" within the site. In this article, a study is made of ventilation and analysis during a $5 \mathrm{mn}$ simulation for three different states: when all the doors and windows are closed, semi-open and open.

In the simulation in which the doors and windows are all open, is used the "open surfaces" in the openings. The access door to fully opened stairwells, has an area of $2.76 \mathrm{~m}^{2}$ for each door (equivalent to a total of $52.44 \mathrm{~m}^{2}$ ), and the windows of the type (aluminium sliding window), with only $50 \%$ of the total area open and half closed, with a total air leakage of $0.5644 \mathrm{~m}^{2}$ for each window (equivalent to a total of $10.7236 \mathrm{~m}^{2}$ ). Including doors and windows open, has a total area of air leakage equivalent to $63.1636 \mathrm{~m}^{2}$. For simulation with everything closed, is used "obstructions" that fill the size of the doors and windows with a total area of leak approximately $0.0140 \mathrm{~m}^{2}$, for each door (equivalent to a total of $0.266 \mathrm{~m}^{2}$ ) and for windows, the area of total leakage for each window is $0.0088 \mathrm{~m}^{2}$ (equivalent to a total of $0.1672 \mathrm{~m}^{2}$ ). Thus, including doors and windows closed, has a total area of air leak equivalent to $0.4332 \mathrm{~m}^{2}$. Finally, the semi-open simulation is organized doors and windows alternately between floors, specifically open in pairs floors with the exception of the floor where the incident occurred and closed on odd floors to the three cases of measurement (Natural ventilation, Pressurization and Dilution).

Natural ventilation, here the study is done without any preventive measure be taken. According to the standard document stipulated by the Chinese code GB50045-95, the total area of the open windows of the stairwell for each 5 floors must not be less than $2 \mathrm{~m}^{2}$ [5]. The building under study in this paper contains a window on each floor, directly to outside of $(1.4 \mathrm{~m} \times 0.8 \mathrm{~m})$.

Pressurization, the pressurization system of the staircase, provides a ventilation to inside the stairwell of $21600 \mathrm{~m}^{3} / \mathrm{h}$, through 6 "fans" positioned alternately (floor 8, 10, 12, 14, 16 and 18) on floors nearest of fire, where each one provides a air flow of approximately $1 \mathrm{~m}^{3} / \mathrm{s}$.

Dilution, in this system the amount of air drawn is equal to the amount that is provided by the "fans". In the case of dilution, extraction of air is taken through five "exhausts", wherein each one extracts $1 \mathrm{~m}^{3} / \mathrm{s}$ of air.

The visibility at the time of evacuation is a very important factor, so it is analyzed that the rate of decrease of light and the visibility is used to describe the situation of the evolution of smoke in the simulation. The most useful quantity for assessing visibility in a space is the light extinction coefficient, $K$ [6]. The intensity of monochromatic light passing a distance $\mathrm{L}$ through smoke, both given by the following equations:

$$
I / I_{0}=e^{-\mathrm{KL}}
$$

where $I$ is the light intensity at the time of exit from the space, $I_{0}$ is the light intensity at the time of going into space, $I / I_{0}$ is the balopticon rate of the space in $\%, K$ is the decreased rate of light $(1 / \mathrm{m})$ and $L$ is the length of the space $(\mathrm{m})$. The decrease in the rate of light is a variable dependent on the mass of smoke per unit volume, as follows:

$$
I=K_{m} \times M_{s}
$$

where $K_{m}$ is the rate of decrease of light per unit mass of smoke $\left(\mathrm{m}^{2} / \mathrm{kg}\right)$ and $M_{s}$ is the mass of smoke per unit volume $\left(\mathrm{kg} / \mathrm{m}^{3}\right)$. Thus, the visibility calculation as follows:

$$
S=C / K
$$

where $S$ is the visibility (m) and $C$ is a non-dimensional constant characteristic of the type of object being viewed through the smoke, i.e. $C=8$ for a light-emitting sign and $C=$ 3 for a light-reflecting sign.

Three parameter control smoke production and visibility; each parameter is input on the REAC line. The $1^{\text {st }}$ parameter is SOOT_YIELD, which is the fraction of fuel mass that is converted to soot if the mixture fraction model is being used. The $2^{\text {nd }}$ parameter is called the MASS_EXTINCTION_COEFFICIENT, and it is the Km in Eq. (2). The $3^{\text {rd }}$ parameter is called the VISIBILITY_FACTOR, the constant $C$ in Eq. (3). It is 3 by default.

Thus, the analyzes performed with the use of a dynamic reading plane "slice", the Fig. 2, Fig. 3 and Fig. 4 show the rates of visibility, after the fire which took $4.5 \mathrm{mn}$ in three ventilation conditions, in which windows and doors were closed, semi-open or completely open. 


\section{B. Grid Sensitivity Analysis}

This section reports on the effect that gird size selection had on simulations undertaken for this study.

The effect that grid size had on the simulations was investigated to determine a optimum grid size that would be adopted for future simulations, as finer grids requires more computational time and power [7]. It is important to determine an appropriate grid size that optimizes solution accuracy and time [8]. Thus, the computational domain in these tests includes the lobby space and the whole space of the staircase.

The grid has been systematically refined until no significant difference is noticed with a cell size reduction and a compromise solution between numerical accuracy and computational cost is achieved. Six different grids size have been assessed, $0.90 \mathrm{~m}, 0.60 \mathrm{~m}, 0.40 \mathrm{~m}, 0.18 \mathrm{~m}, 0.15 \mathrm{~m}$ and $0.12 \mathrm{~m}$. For this study, constant HRR fires of 5MW have been simulated and averaged quasi-steady conditions at different locations have been considered. The results have been compared between them, and with the finest grid results, to quantify grid independence. In LES it is not possible to archive perfect grid independence although little variations can be theoretically expected between grids if they are fine enough [9], [10]. Table II shows the temperature predictions in the stairwell for each grid. It can be observed that the temperature values and the relative errors for the three coarser grids are quite large. The temperature differences are lower than $10 \%$ at the upper parts, above $18 \mathrm{~m}$ high, from $0.12 \mathrm{~m}$ cells. Thus, it could be concluded that any of the three finer grids $0.18 \mathrm{~m}, 0.15 \mathrm{~m}$ and $0.12 \mathrm{~m}$ cells could be valid for simulating the fire tests.

TABLE II: Plume TEMPERATURES AT DIFFERENT HeIGHTS ACCORDING TO THE GRID SIZE

\begin{tabular}{lllllll}
\hline \hline \multirow{2}{*}{$\begin{array}{l}\text { Height } \\
\text { plume }\end{array}$} & \multicolumn{7}{l}{ Temperature predictions $\left({ }^{\circ} \mathrm{C}\right)$} \\
\cline { 2 - 7 } & $0.90_{\mathrm{m}}$ & $0.60_{\mathrm{m}}$ & $0.40_{\mathrm{m}}$ & $0.18_{\mathrm{m}}$ & $0.15_{\mathrm{m}}$ & $0.12_{\mathrm{m}}$ \\
\hline at $18 \mathrm{~m}$ & 99 & 110 & 64 & 74 & 81 & 78 \\
at $12 \mathrm{~m}$ & 173 & 152 & 80 & 136 & 160 & 129 \\
at $6 \mathrm{~m}$ & 333 & 226 & 116 & 487 & 503 & 293 \\
Exhaust & 64 & 66 & 49 & 56 & 58 & 53 \\
\hline \hline & \multicolumn{7}{c}{ Relative error respect to finer grid $(\%)$} \\
\cline { 2 - 7 } & $0.90_{\mathrm{m}}$ & $0.60_{\mathrm{m}}$ & $0.40_{\mathrm{m}}$ & $0.15_{\mathrm{m}}$ & $0.12_{\mathrm{m}}$ \\
\hline at $18 \mathrm{~m}$ & 34 & 49 & 14 & 9 & 5 \\
at $12 \mathrm{~m}$ & 27 & 12 & 41 & 18 & 5 \\
at $6 \mathrm{~m}$ & 32 & 54 & 76 & 3 & 40 \\
Exhaust & 14 & 18 & 13 & 4 & 5 \\
\hline \hline
\end{tabular}

\section{RESUlt ANALYSIS}

Next, the fire-induced transient conditions within the stairwell are studied. In this section, the main results from the visibility tests and pressurization as well as from the comparisons between them are reported and discussed. Results in three different ventilation systems are considered: with natural ventilation system, it is noticed that the smoke tends to occupy most of the stairs, due to heat pressure and stack effects; in the pressurization system, we perceive, that the smoke was prevented from entering the staircase; and finally for the dilution system, only a little smoke was allowed to enter the staircase.

Analyzing comparatively the different ventilation systems, we realize that the natural ventilation system provides a measure of escape less favorable than the dilution system, which in turn improves the environment for evacuation, however, with the permission of some smoke entry on the stairs, under the stack effect produced by negative pressure. While there is some open doors, accelerates the flow under the stack effect so that there is a rapid rise of smoke, while on the other hand, a certain amount of smoke is pushed out of the stairs to enter the upper level. Thus it is seen that both effects are approximately equal and neutralized, which does not allow us to see great changes of visibility in reading plans, presented at Fig. 2, Fig. 3 and Fig. 4.

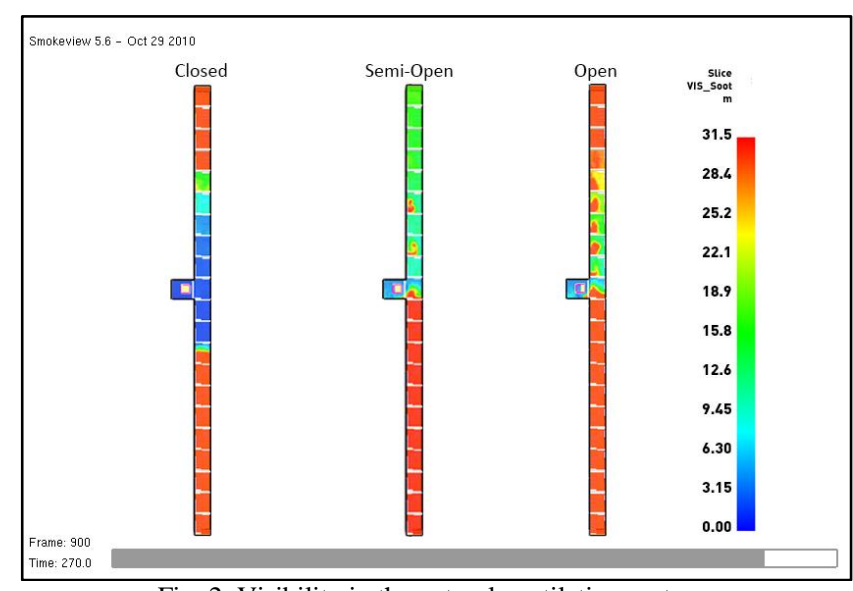

Fig. 2. Visibility in the natural ventilation system

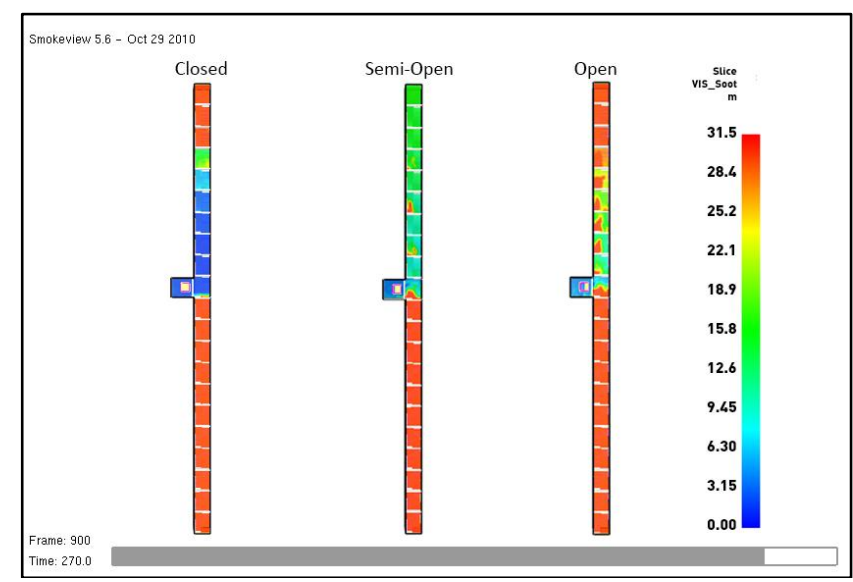

Fig. 3. Visibility in the pressurization system.

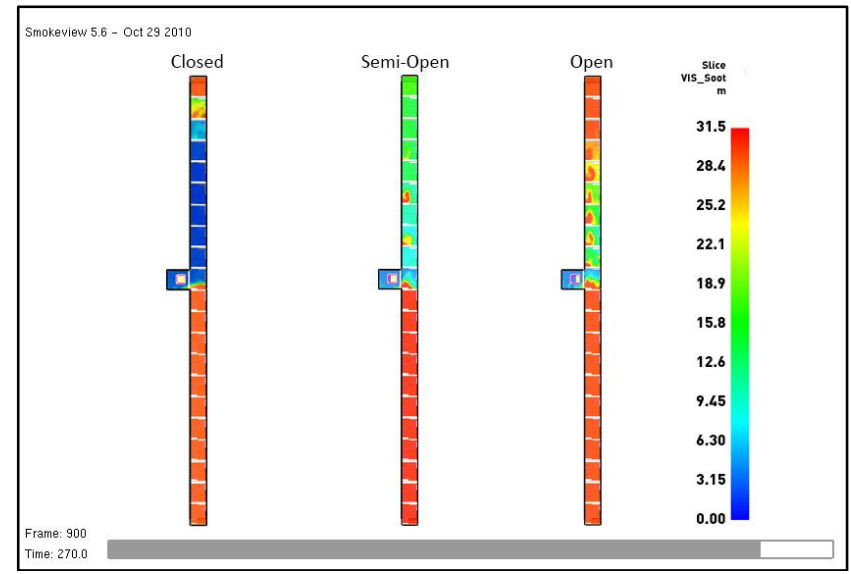

Fig. 4. Visibility in the dilution system.

In order to frame the interpretations above are considered minimum visibilities of $5 \mathrm{~m}$ for unfamiliar and $13 \mathrm{~m}$ for people that are familiar with the building [6]. Thus, the Fig. 5(a)-(c) show the visibility in three ventilation conditions for the 
states (closed, semi-open and open) that:

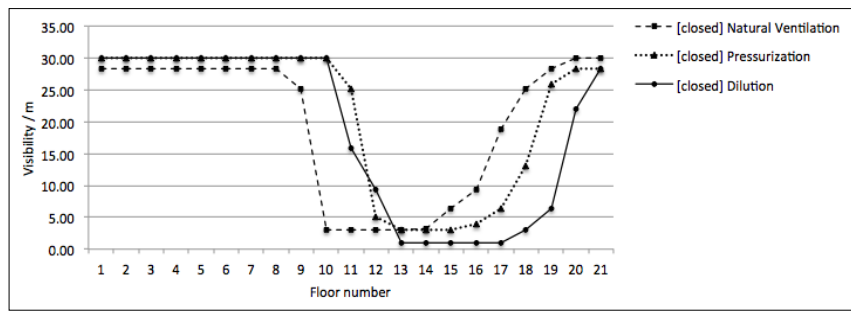

(a)

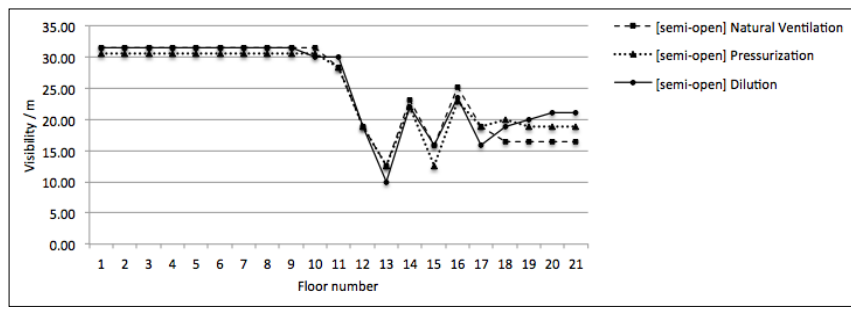

(b)

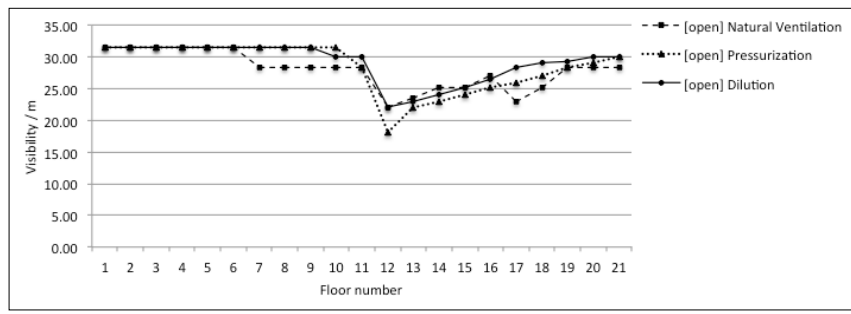

(c)

Fig. 5. Visibility at state: closed in (a), semi-open in (b) and open in (c).

In natural ventilation system the visibility hovers around: Closed: from 10th till $14^{\text {th }}$ floor the visibility is less than $5 \mathrm{~m}$, in $15^{\text {th }}$ and $16^{\text {th }}$ the visibilities vary around $10 \mathrm{~m}$, slightly less than the required code, and from $17^{\text {th }}$ the visibility exceeds $18 \mathrm{~m}$; Semi-open: with the exception of the $13^{\text {th }}$ floor with $12.6 \mathrm{~m}$, the others floors visibility exceeds $15 \mathrm{~m}$; Open: in this case the visibility is more than $20 \mathrm{~m}$. Given the pressurization system, exerting a pressure that prevents the smoke from entering the stairwell, so the visibility is: Closed: between $12^{\text {th }}$ to $16^{\text {th }}$ floor the visibility is less than $5 \mathrm{~m}$, in $17^{\text {th }}$ and $18^{\text {th }}$ is between $5 \mathrm{~m}$ to $13 \mathrm{~m}$ and the others is greater than $25 \mathrm{~m}$; Semi-open: with the exception of the $13^{\text {th }}$ and $15^{\text {th }}$ floor with $12.6 \mathrm{~m}$, the others floors visibility exceeds $15 \mathrm{~m}$. Open: with the aid of the circulation of airflows, the visibility is more than $18 \mathrm{~m}$. While the dilution system, the visibility is: Closed: the lowest visibility occurred between $13^{\text {th }}$ to $18^{\text {th }}$ floor with less than $3.5 \mathrm{~m}$, the $12^{\text {th }}$ is $9.45 \mathrm{~m}$, allowing visibility exceeding $15 \mathrm{~m}$ in other floors. Semi-open: with the exception of the $13^{\text {th }}$ floor with $10 \mathrm{~m}$, the other floors visibility exceeds $15 \mathrm{~m}$. Open: here, the visibility is clearly greater than $21 \mathrm{~m}$.

Now on the other hand, looking at differential pressure of the fire that remained burning for $4.5 \mathrm{mn}$, where is perceived by Fig. 6, Fig. 7 and Fig. 8, with all doors and windows closed, in three different ventilation conditions, the stack effect caused by the temperature difference between the inside and the outside, obviously occurred in stairwell.

One realizes that a negative pressure caused by stack effect occurred in the first 8 floors below the $12^{\text {th }}$ floor, meaning that if the fire appears in these floors, the smoke quickly spread to the stairs. In this analysis, the Fig. 9 exemplifies the three ventilation conditions for the state in which all doors and windows are closed.

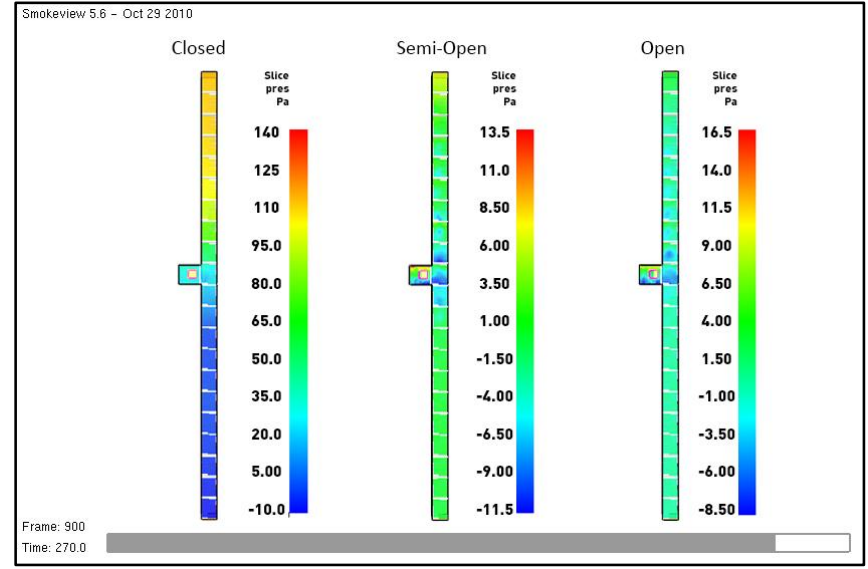

Fig. 6. Differential pressure in natural ventilation system.

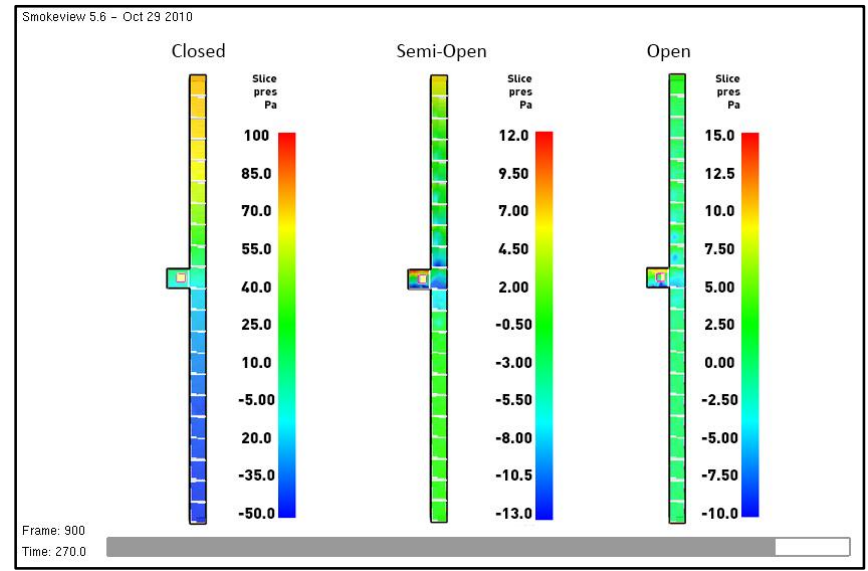

Fig. 7. Differential pressure in pressurization system.

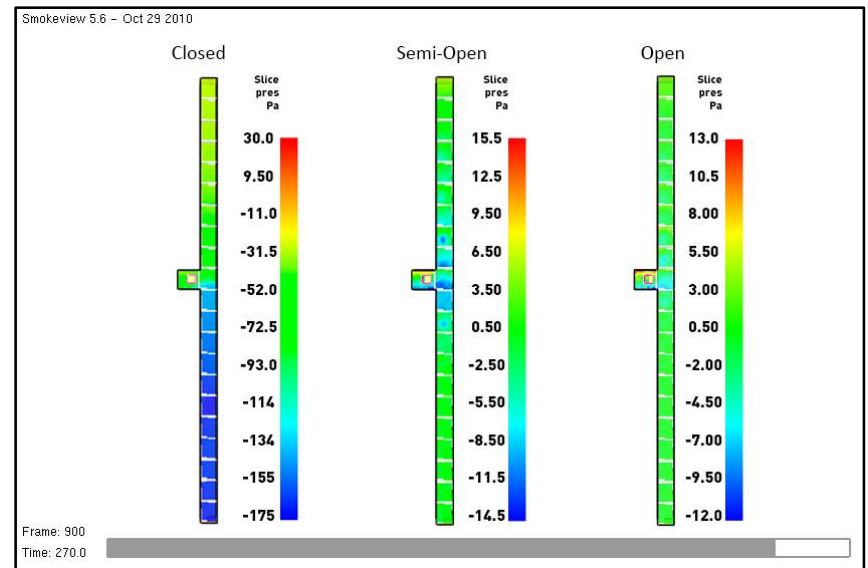

Fig. 8. Differential pressure in dilution system.

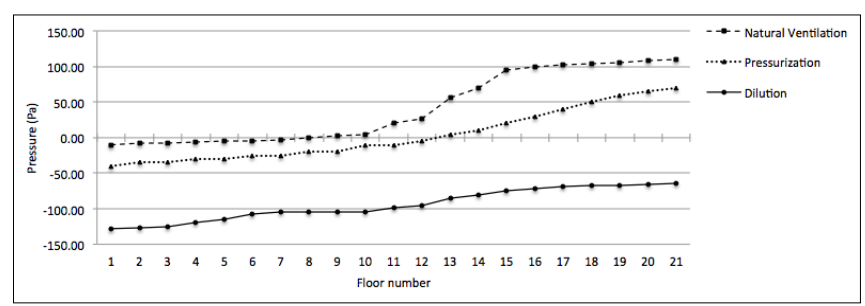

Fig. 9. Differential pressure in 3 ventilation conditions in the closed state.

In natural ventilation, pressurization when in the closed state reaches the bottom of a pressure $-10 \mathrm{~Pa}$ at the top reaches $110 \mathrm{~Pa}$. If this pressure increases at the bottom, it tends to be much higher in the upper part, consequently very high pressures, difficult to open the doors, affecting the evacuation. Considering the open state, it turns out that the pressure is 
evenly distributed when the greatest pressure is less than 6Pa. On the other hand, the pressurization in the closed state exerts a very high pressure on the top of the staircase, thus creating a difficulty to open the exit door. While the measurement of pressure is $-40 \mathrm{~Pa}$ on the first floor, however it tends to achieve $70 \mathrm{~Pa}$ on top. The result of this system is still unsatisfactory since it is not easy to open the door. In the dilution system, although the negative pressures occurring in the closed state, but uniformly distributed on the height change, thus the best result is given that there is less pressure difference. With some doors open in three conditions, the pressure difference was slightly lower.

\section{Summary}

According to what has been mentioned in at point 2.1 and summarized in Table III, was run 9 simulation of $5 \mathrm{mn}$ each. Also the same table summarizes the ratings of the three cases of ventilation, for the simulation reading of visibility and differential pressure.

TABLE III: TYPES OF READING AND SIMULATION RESULTS

\begin{tabular}{|c|c|c|}
\hline \multicolumn{3}{|c|}{ Visibility and Differential Pressure } \\
\hline Nat. Ventilation & Pressurization & Dilution \\
\hline Closed & Closed & Closed \\
\hline Semi-open & Semi-open & Semi-open \\
\hline Open & Open & Open \\
\hline Ventilation System & Differential Pressure & Visibility \\
\hline Nat. ventilation & Acceptable & Unacceptable \\
\hline Pressurization & Unacceptable & Very good \\
\hline Dilution & Very good & Acceptable \\
\hline
\end{tabular}

Considering the closed, semi-open and open state, the objective is to improve the maximum visibility evacuation. In this sense, is can increase the amount of ventilation so that it reaches the ideal requirements. In the high buildings and considering the cases of large temperature difference between the indoor and the outdoor, the pressurization system, it is recommended that buildings be built a zone of refuge dividing the staircase in the middle, so as to weaken the pressure difference between the first and last floor, caused by stack effect.

\section{CONCLUSION}

In the simulation model proposed in this paper, it was possible to control the pressure differential, improving the performance of the mechanical ventilation system, and also allowed increasing distance visibility, including keep the doors open during evacuation process in case of emergency. While the effectiveness of existing stairs pressurization systems depends primarily on maintaining the predominantly closed doors to keep the mass air when necessary. However, regarding the optimal amount of air exchange for the system, one needs a more complete and comprehensive investigation. In this sense and centred in the methodology of projects based on performance, the future work will further validate the model, studying the amount of exchange ideal air into the system and compare these experimental data and the calculated results with simulation models of the evacuation zones of higher flow of occupants according to the structure for a typical stairwell model.

\section{ACKNOWLEDGMENT}

This research was supported in part by the National Science Foundation of China (Grants \#61170202, \#41371420, \#61202287, \#61170135), Wuhan Municipal Key Scientific and Technological Projects Funding (Grant \#201210121029), the Fundamental Research Funds for the Central Universities (Grant \#2014-YB-016) and also by Department of Investigation of the University of Cape Verde. The funders had no role in study design, data collection and analysis, decision to publish, or preparation of the manuscript.

\section{REFERENCES}

[1] G. W. Woodruff, "Smoke movement in elevator shafts during a high-rise structural fire," Fire Safety Journal, vol. 4, pp. 1-15, 2008.

[2] J. Jae-Hun, L. Jae-Han, and S. Seung-Yeong, "Characteristics of pressure distribution and solution to the problems caused by stack effect in high-rise residential buildings," Building and Environment, vol. 42, pp. 263-277, 2007.

[3] M. Khoukhi, H. Yoshinoa, and J. Liu, "The effect of the wind speed velocity on the stack pressure in medium-rise buildings in cold region of china," Building and Environment, vol. 42, no. 1081-1088, 2007.

[4] Y. Cong, "Performance-based design of structure fire protection," Dissertation, Tianjin: Tianjin University of Technology, 2007.

[5] GB/T 50045-2005, Code for Fire Protection Design of Tall Buildings, 2005.

[6] L. Yin-Ging, Fire Protection Engineering for Buildings, Beijing: Chemical Industry Press, 2004.

[7] L. Ming-Liang, "Smoke control methods in high-rise building stairwell," Henan Fire Protection, vol. 9, no. 24-25, 2009.

[8] A. Bounagui and N. Benichou, Literature Review on the Modeling of Fire Growth and Smoke Movement, Canada: National Research Council, 2003.

[9] S. B. Pope, "Computations of turbulent combustion: Progress and challenges," Proceedings of the Combustion Institute, vol. 23, pp. 591-612, 1990.

[10] K. B. McGrattan, Fire Dynamics Simulator (Version 5) User's Guide, Gaithersburg, Maryland, USA: M. NIST Special Publication, 2010.

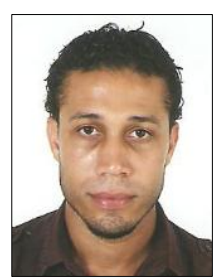

Aristides Silva was born in Cape Verde in 1978, received his M.Sc. Eng. degree in the field of computer science - information systems from University of Aveiro, Portugal in 2010 and 2015 was his last year as a $\mathrm{Ph} . \mathrm{D}$. student in the field of computer application technology - graphic computing from the School of Computer Science and Technology, Wuhan University of Technology, China.

Since 2008, he also holds the position of assistant graduate teacher at the Department of Science and Technology, Multimedia Technologies and Informatics Engineering, the University of Cape Verde. His research interests include, image processing and understanding, 3D visualization techniques and application of computer science in dynamic simulation of fluids.

Shengwu Xiong received his M.Sc. Eng. and Ph.D. degrees in the field of computer software and theory from Wuhan University, China in 1997 and 2003 , respectively.

$\mathrm{He}$ is currently a professor in the School of Computer Science and Technology, the Wuhan University of Technology, China. His research interests include, intelligent computing, machine learning and pattern recognition.

Hussain Aamir received his M.Sc. Eng. degree in the field of MBA(IT) from the Allama Iqbal Open University in 2011 and 2015 was his last year as a PhD student in the field of computer application technology from the School of Computer Science and Technology, Wuhan University of Technology, China.

His research interests include wireless body area network, healthcare, fuzzy logic and internet of things. 

Medical Electronics and Image Processing 
